\title{
O CHORO, A APRECIAÇÃO MUSICAL ATIVA E O DESENVOLVIMENTO COGNITIVO E MUSICAL DOS ALUNOS DOS ANOS INICIAIS DO ENSINO FUNDAMENTAL
}

\author{
Choro, active musical appreciation and \\ cognitive and musical development of \\ students in the early years of elementary \\ school
}

\author{
Choro, apreciación musical activa y \\ desarrollo cognitivo y musical de los \\ estudiantes en los primeros años de la \\ escuela primaria
}

Camile Tatiane de Oliveira Pinto
Universidade Federal do Paraná
camiletatiane@gmail.com

Ana Paula Peters

Universidade Estadual do Paraná - campus Curitiba I - EMBAP anapaula.peters@unespar.edu.br

\begin{abstract}
Resumo: Este artigo apresenta uma pesquisa que teve como objetivo discutir e analisar a utilização do repertório instrumental brasileiro do choro nas aulas de música dos anos iniciais do ensino fundamental. Este gênero, predominantemente instrumental, pode oferecer diferentes oportunidades de desenvolvimento musical e cognitivo no contexto do ensino básico. Considerando os seus modos de transmissão e contexto, discutimos a apreciação musical ativa como forma de viabilizar o engajamento dos alunos com o repertório instrumental proposto. A ativação da escuta utilizando o corpo, a voz, o movimento e os instrumentos possibilitaram a preservação da natureza experiencial do choro e, com isso, a valorização de seu conteúdo sonoro e expressivo. A análise quantitativa e qualitativa dos dados coletados trouxe informações importantes sobre o potencial da apreciação musical ativa do choro para o ensino e aprendizagem musical no ensino básico. Com isso, busca-se valorizar a compreensão simbólica da música e acrescentar elementos e dados para que a música instrumental brasileira integre currículos e práticas escolares.
\end{abstract}

Palavras-chave: Choro. Ensino fundamental. Apreciação musical ativa. Música instrumental brasileira.

\begin{abstract}
This article presents research that aimed to discuss and analyze the use of the Brazilian instrumental repertoire of choro in music classes in the early years of elementary school. This predominantly instrumental genre can offer different opportunities for musical and cognitive development in the context of basic education. Considering their modes of transmission and context, we discuss active musical appreciation as a way to enable student engagement with the proposed instrumental repertoire. The activation of listening using the body, voice, movement and instruments made it possible to preserve the experiential nature of choro and, with that, the enhancement of its sound and expressive content. The quantitative and qualitative analysis of the collected data brought important information about the potential of active musical appreciation of choro for teaching and learning music in basic education. With this, we seek to value the symbolic understanding of music and add elements and data so that Brazilian instrumental music integrates curricula and school practices.
\end{abstract}

Keywords: Choro. Elementary school. Active musical appreciation. Brazilian instrumental music. 


\begin{abstract}
Resumen: Este artículo presenta una investigación que tuvo como objetivo discutir y analizar el uso del repertorio instrumental brasileño del choro en las clases de música en los primeros años de la escuela primaria. Este género predominantemente instrumental puede ofrecer diferentes oportunidades para el desarrollo musical y cognitivo en el contexto de la educación básica. Teniendo en cuenta sus modos de transmisión y contexto, discutimos la apreciación musical activa como una forma de permitir el compromiso de los estudiantes con el repertorio instrumental propuesto. La activación de la escucha a través del cuerpo, la voz, el movimiento y los instrumentos permitió preservar el carácter vivencial del choro y, con ello, potenciar su contenido sonoro y expresivo. El análisis cuantitativo y cualitativo de los datos recopilados aportó informaciones importantes sobre el potencial de la apreciación musical activa del choro para enseñar y aprender música en la educación básica. Con esto, buscamos valorar la comprensión simbólica de la música y agregar elementos y datos para que la música instrumental brasileña integre los planes de estudio y las prácticas escolares.
\end{abstract}

Palabras clave: Choro. Enseñanza fundamental. Apreciación musical activa. Música instrumental brasileña.

\title{
INTRODUÇÃO
}

"Mas quando a música começa?" é uma frase que, isolada do seu contexto, pode representar a impaciência gerada pela expectativa ou pelo desejo de ouvir música. Entretanto, quando a frase é relacionada a uma situação em que a música já começou a ser executada, outros cenários e interpretações podem ser pensados. Este artigo apresenta uma pesquisa motivada por essa frase, e que foi proferida durante uma aula de música com alunos e alunas dos anos iniciais do ensino fundamental. A pesquisa explorou e analisou as possibilidades de desenvolvimento musical na escola por meio do repertório instrumental do choro, com ênfase na apreciação musical ativa proposta por Wuytack e Palheiros (1995).

$\mathrm{Na}$ ocasião, a escuta do choro "O gato e o canário" de Pixinguinha havia sido iniciada, e logo quando a reexposição do tema A iria começar, um aluno questionou: "Mas quando a música começa?" Nesse caso, não se tratava de uma condição ou deficiência que prejudicasse a audição. Segundo explicou, estava aguardando a entrada do cantor ou cantora, fato que definiria para ele, o começo da música. Ao ser indagado sobre a música que já estávamos ouvindo, ele reiterou: "Não, mas quando começa mesmo?"

A canção é um referencial musical presente na infância e, além dela, as vocalizações, parlendas e jogos cantados integram as expressões vocais das crianças. No ambiente escolar, o canto e as brincadeiras cantadas são parte das aulas de música (Ilari, 2009) e também estão presentes nas manifestações musicais não sistematizadas, como no recreio, intervalo e em outros momentos de interação entre as crianças (Romanelli, 2009). Por outro lado, em geral a música instrumental não está presente no cotidiano das crianças, que deixam de vivenciar esse tipo de discurso musical e de construir significados sem a mediação de um texto literário (Almeida; Levy, 2010). A presença da música instrumental - em especial, a brasileira - não é reduzida apenas na infância; esse tipo de repertório não alcança o grande público, e mesmo no ambiente acadêmico não são muitas as pesquisas sobre a música instrumental brasileira (Assis; Barbeitas; Lana; Cardoso Filho, 2009).

Além da presença, a utilização do repertório instrumental implica também considerar os meios que possibilitem a estimulação da escuta dos 
envolvidos, com o objetivo de favorecer o envolvimento e a compreensão do discurso musical. A apreciação musical ativa, que "[...] implica o envolvimento activo do ouvinte, e para o qual são necessárias a experiência e a aprendizagem" (Wuytack; Palheiros, 1995, p. 13), foi desenvolvida pelo compositor e educador musical belga Jos Wuytack. Apoiando-se nas ideias de Orff-Schulwerk, entende a experiência musical a partir da integração de três formas de expressão: verbal (poesia, drama e teatro), musical (cantar, tocar, criar, improvisar) e corporal (movimento, mímica e dança). A apreciação musical ativa foi a modalidade central utilizada na pesquisa, e, por meio dela, a criação e a performance foram oportunizadas, garantindo o envolvimento ativo e coletivo dos alunos e mantendo a natureza experiencial e coletiva do choro.

\section{O CHORO NA ESCOLA}

O choro é um dos primeiros gêneros da música popular brasileira urbana, e uma de suas características é a de que o seu repertório é predominantemente instrumental (Diniz, 2003). Grande parte de suas composições são de caráter desafiador, malandro, brincalhão (Piedade, 2011), e o improviso é uma prática frequente entre os músicos, momento este em que podem expressar-se criativa e tecnicamente. No cotidiano, a prática do choro ocorre em rodas, que são "[...] o espaço de transmissão, criação, experimentação, improvisação e convivência dos músicos que se aproximam deste gênero musical” (Peters, 2016, p. 61). Muitas vezes os músicos tocam sem o uso de partitura, e é pela vivência, pelo "ouvido" e pela interação que se dá a aprendizagem do choro (Souza, 2012).

Os títulos dos choros fornecem indícios para uma compreensão inicial de como a música foi pensada, organizada e estruturada. Ainda que em algumas composições a relação entre o título e a comunicação de uma ideia não pareça evidente, o enunciado de um discurso é uma característica do repertório do choro. Essas composições são construídas a partir de uma ideia que estrutura o discurso musical, um fio condutor que guia o intérprete e o ouvinte na comunicação do sentido expressivo da obra; esse discurso é reforçado pelos aspectos descritivos, metafóricos, simbólicos e onomatopaicos (Lopes, 2019), conforme denotam os títulos e o material musical de "Pula sapo", "Marreco quer água” (ambos de Pixinguinha), “André do sapato novo” (Victor Correia), "Escorregando" (Ernesto Nazareth), "Bem-te-vi atrevido" (Lina Pesce), "Não insistas, rapariga" (Chiquinha Gonzaga) e "Canarinho teimoso" (Altamiro Carrilho). Há, na retórica do choro, uma riqueza de oportunidades no sentido de estimular as transformações metafóricas que, de acordo com as explicações propostas por Swanwick (2003), ocorrem quando a partir do som são produzidos os gestos expressivos que são organizados em estruturas que se relacionam com a compreensão simbólica da música.

A música instrumental na escola, em geral, é trabalhada a partir do repertório da música de concerto europeia. Esse assunto costuma integrar currículos, publicações e práticas dos professores, e muitas orquestras 
ofertam programas específicos de formação de plateia para crianças. Nos cursos superiores de música, há também a hegemonia da música clássica europeia e dos modos de ensino que a acompanham, o que mantém afastados dos professores em formação outros repertórios e modos de aprender e ensinar (Queiroz, 2017). Entre os espaços que a música instrumental brasileira tem a ocupar está o ambiente escolar, onde pode contribuir para a democratização do patrimônio cultural nacional, que é um dos objetivos da educação básica (Cury, 2008). Nesse sentido, a Base Nacional Comum Curricular (BNCC) apresenta como uma das competências a serem desenvolvidas na área de Arte no ensino fundamental:

Pesquisar e conhecer distintas matrizes estéticas e culturais especialmente aquelas manifestas na arte e nas culturas que constituem a identidade brasileira -, sua tradição e manifestações contemporâneas, reelaborando-as nas criações em Arte (Brasil, 2017, p. 196).

A utilização da música brasileira na sala de aula deve incluir as suas expressões instrumentais, como o choro. Não se trata de invalidar ou privilegiar qualquer tipo de repertório, e sim de investigar as possibilidades do repertório brasileiro, cujo potencial ainda pode ser explorado na sala de aula (Fucci-Amato, 2012). O gênero choro é parte dos conteúdos de determinados livros didáticos de música, onde são propostas atividades a seu respeito tais como conhecer a biografia dos compositores, conhecer os instrumentos e o repertório. Essas atividades privilegiam as habilidades que envolvem leitura e escrita, que, segundo Green (2008, p. 67), são habilidades mais valorizadas do que o ouvir. O ensino dos instrumentos do choro na escola foi enfocado em pesquisas acadêmicas (Amaral; Cordeiro; Goulart, 2010; Alves da Silva, 2010; Bertho; Joly, 2010; Yaunner, 2013), porém o ensino instrumental não se configura como um objetivo único do ensino fundamental, ainda que possa fazer parte das aulas.

De acordo com Green (2012), mesmo quando o repertório popular está presente na sala de aula, os seus processos de prática, aprendizagem e transmissão são ignorados ou deturpados. Para a autora, o contexto escolar pode modificar os significados das experiências musicais, fazendo com que a música popular seja ensinada nos mesmos moldes da música clássica; Green (2012, p. 68) afirma que

se suas práticas autênticas de produção e transmissão estão ausentes do currículo, e se nós não formos capazes de incorporá-las em nossas estratégias de ensino, estaremos lidando com um simulacro, ou com um espectro da música popular em sala de aula, e não com a coisa em si.

Sandroni (2000, p. 20) também alerta, sobre o ensino de música popular na escola, que "é possivel tratar as músicas populares como conteúdos a serem incorporados aos currículos de música, mas ensinados segundo 
métodos alheios a seus contextos originais". A questão que se apresenta então é estimular a escuta e o envolvimento com o repertório instrumental do choro no contexto escolar, coletivo, não direcionado a prática instrumental e que possa preservar a essência prática desse gênero. Nesse sentido, os métodos ativos em educação musical se apresentam com uma possibilidade para a aproximação com essa prática musical, por terem como denominador comum a vivência musical antes da teoria (Penna, 2013), e entre eles está a apreciação musical ativa.

É oportuno nos anos iniciais do ensino fundamental estimular diferentes formas de envolvimento com diferentes repertórios, pois na pré-adolescência o canto, a dança, o movimento e o gosto musical podem ser ressignificados (Ilari, 2009). Para Sloboda (2008), é no período entre os 5 e os 10 anos de idade que ocorre, no desenvolvimento musical, uma crescente conscientização reflexiva sobre as estruturas e os padrões da música. Isso significa "[...] uma habilidade crescente de classificar explicitamente a música como algo que se ajusta a regras e estilo, por uma melhora crescente em tarefas de memória e percepção sobre as sequências que conformam com as regras" (Sloboda, 2008, p. 284). Além disso, na etapa dos anos iniciais devemos garantir a possibilidade de o aluno "[...] se expressar criativamente em seu fazer investigativo" (Brasil, 2017, p. 199), o que pode ocorrer por meio das aulas de música. As propostas desenvolvidas nesta pesquisa, a partir do repertório instrumental do choro, valeram-se das diferentes formas de se relacionar com a música e desse momento do desenvolvimento em que se situam os alunos dos anos iniciais, estimulando o seu desenvolvimento cognitivo e musical.

\section{A PESQUISA}

Foi realizada uma pesquisa-ação, na qual a professora pesquisadora ministrou oito aulas de música em uma turma de 33 alunos do $4^{\circ}$ ano do ensino fundamental - anos iniciais - de uma escola pública da cidade de Curitiba. A investigação de tópicos relacionados com a atuação dos professores/investigadores e com questões sobre a aprendizagem, inovação e aprimoramento são contribuições da pesquisa-ação no cotidiano escolar. Ressaltamos, ainda, o enriquecimento que esse tipo de pesquisa traz para a formação continuada para termos professores reflexivos, que busquem aprimorar e ampliar as oportunidades de ensino dos seus alunos. Desse modo,

os professores não só contribuem para melhorar o trabalho nas suas escolas, mas também ampliam o seu conhecimento e a sua competência profissional através da investigação que efectuam. Daqui emerge a problemática da investigação-acção como sendo um recurso apropriado para a melhoria da educação e o desenvolvimento dos seus profissionais (Máximo-Esteves, 2008, p. 18-19). 
Fundamentado no currículo do ensino fundamental I para a educação municipal de Curitiba (Curitiba, 2016), o planejamento das aulas explorou os aspectos característicos do repertório instrumental do choro a partir de atividades que relacionavam o material temático com a participação fisica e mental dos alunos. O choro foi o repertório central utilizado nas intervenções da pesquisa, mas outros gêneros foram utilizados pela professora regente dentro da disciplina de Arte. As atividades foram planejadas considerando a integração das formas de expressão verbal, musical e corporal (Wuytack; Palheiros, 1995):

- Expressão corporal, desenvolvida a partir dos motivos rítmicos ou melódicos dos choros por meio da percussão corporal, movimentos com ou sem deslocamento. Por exemplo:

Excerto de "Brejeiro", de Ernesto Nazareth

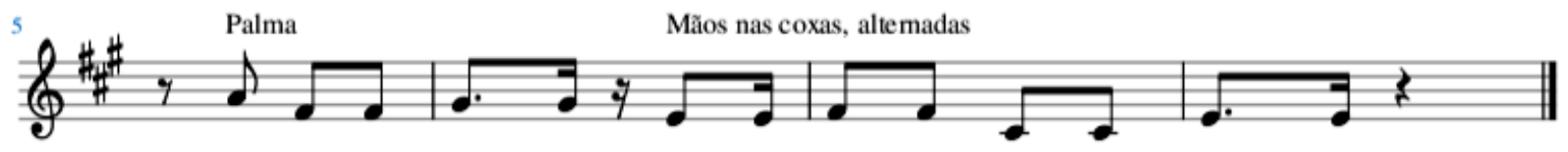

Fonte: Oliveira Pinto (2020).

- Expressão musical trabalhada por meio da prática instrumental com objetos e com instrumentos de pequena percussão, o que incluiu a composição em duplas e a improvisação. No exemplo abaixo, os alunos dividiram-se em duas vozes, tocando o motivo com instrumentos de pequena percussão:

Motivo rítmico adaptado a partir de "Marreco quer água", de Pixinguinha

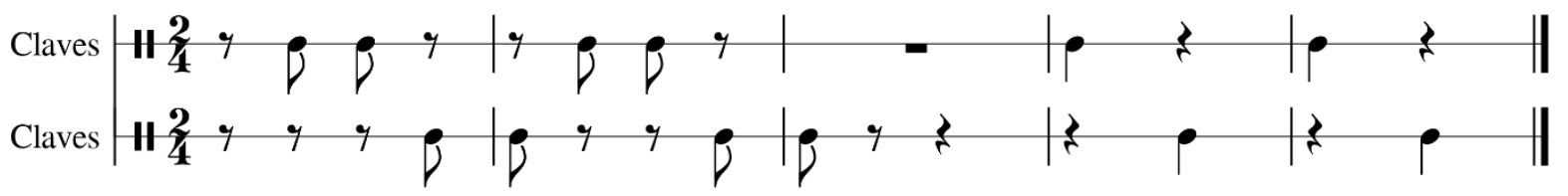

Fonte: Oliveira Pinto (2020). 
- Expressão verbal, que foi oportunizada com a fala de um trava-línguas, recitado de acordo com o ritmo da parte A da peça "Odeon", de Ernesto Nazareth:

Motivo de "Odeon", de Ernesto Nazareth, associado ao trava-linguas

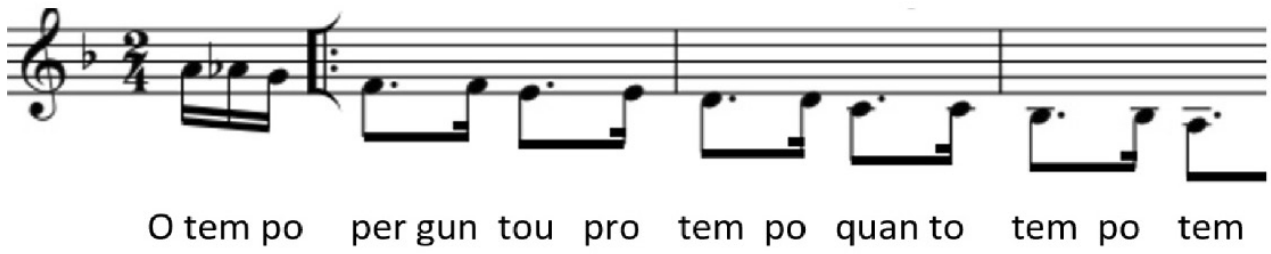

Fonte: Oliveira Pinto (2020).

A criatividade e a autonomia dos alunos foi oportunizada em momentos de improvisação e composição de acompanhamentos instrumentais, percussão corporal, jogos de mãos e movimento nos choros trabalhados. A forma rondó é uma das características frequentes no choro, e dessa forma buscamos associar cada parte a uma atividade, dedicando sempre uma das partes à criação e improvisação. Por exemplo, na música “Odeon”, a parte A foi dedicada à expressão verbal, a parte B, à expressão musical e a parte C, à criação de um acompanhamento com percussão corporal.

Os dados foram coletados por meio de um questionário constituído por três perguntas abertas, que foi aplicado em dois momentos da pesquisa: na primeira aula, antes do desenvolvimento das atividades previstas, e na última aula, após as intervenções. Com isso, investigamos a relação entre a condição inicial e final dos alunos mediante a intervenção pedagógica. As três questões se correlacionam com os elementos do discurso musical materiais sonoros, caráter expressivo e forma de (Swanwick, 1994). As perguntas foram: 1) Quais sons você percebeu nessa música? 2) Como são as partes da música? 3) O que essa música fez você imaginar?

As perguntas abertas do questionário permitiram a ampliação das possibilidades de respostas por parte dos alunos pesquisados, o que gerou o estabelecimento das categorias de análise. Para o uso dos questionários foi elaborado um protocolo que otimizou a sua aplicação. De modo sucinto, o procedimento adotado a partir do protocolo foi o seguinte: os alunos ouviram a peça " 1 x 0" de Pixinguinha do início até o minuto 1'28", três vezes. Foram orientados a ouvir atentamente na primeira vez e, na segunda, ouviram e responderam às perguntas. Por fim, ouviram a terceira vez e então puderam confirmar ou retificar as suas respostas. Essa sequência aconteceu na primeira aula, antes da realização de qualquer atividade, e foi repetida da mesma forma após as aulas ministradas. 
A análise de dados valeu-se de procedimentos estatísticos (quantitativos) que fundamentaram as inferências da análise qualitativa, relacionando-a com o modelo espiral do desenvolvimento musical de Swanwick e Tillman (1986). Ainda que permaneçam válidas as discussões sobre a relação do modelo com a teoria piagetiana (Caregnato, 2013; Maffioletti, 2005), na pesquisa a espiral viabilizou a compreensão sobre a influência do meio, da manipulação e da experimentação na aquisição de habilidades. Além disso, permitiu o entendimento sobre o repertório do choro como uma forma simbólica de compartilhamento de sistemas de significados.

\section{ANÁLISE E DISCUSSÃO}

Dos 33 alunos participantes, foram analisadas as respostas de 27 alunos; foram excluidas as respostas de alunos que participaram apenas da primeira ou da última coleta. As respostas dos questionários foram analisadas por meio do teste não paramétrico de McNemar, que é utilizado para comparar frequências oriundas de amostras pareadas, principalmente com variáveis qualitativas (Siegel, 1956). Os dados foram analisados também em perspectiva qualitativa a partir do modelo espiral de Swanwick e Tillman (1986). Neste estudo temos um conjunto de dados com duas amostras pareadas, isto é, cada indivíduo é avaliado antes e depois de uma intervenção. Nesse tipo de estudo o indivíduo é o seu próprio controle, e busca-se verificar a correlação entre os indivíduos após a intervenção. O teste que verifica a significância de qualquer mudança observável é realizado a partir de uma tabela de frequências pareadas:

Tabela 1: Frequência de amostras pareadas.

\begin{tabular}{|c|c|c|c|c|}
\hline & & \multicolumn{2}{|c|}{ Amostra I } & \multirow{2}{*}{ Total } \\
\hline & & I Presente & I Ausente & \\
\hline \multirow{2}{*}{ Amostra II } & II Presente & A & B & $a+b$ \\
\hline & II Ausente & $\mathrm{C}$ & $\mathrm{D}$ & $c+d$ \\
\hline \multicolumn{2}{|c|}{ Total } & $a+c$ & $b+d$ & $\mathrm{n}=\mathrm{a}+\mathrm{b}+\mathrm{c}+\mathrm{d}$ \\
\hline
\end{tabular}

Fonte: Siegel (1956).

Considerando a distribuição qui-quadrado com 1 grau de liberdade, na análise desse conjunto de dados vamos considerar um $\mathrm{p}$-valor $\alpha=0,05$ para significância das diferenças.

Os resultados foram divididos em três instâncias: Materiais Sonoros, Forma e Caráter Expressivo, que correspondem à análise das questões 1, 2 e 3 , respectivamente. De cada uma das instâncias originaram-se as categorias de análise e os resultados apresentados a seguir. 


\section{INSTÂNCIA MATERIAIS SONOROS}

A partir da pergunta "Quais sons você percebeu nessa música?" as respostas obtidas na instância Materiais Sonoros derivaram as seguintes categorias: a) instrumentos que não fazem parte da gravação; b) instrumentos que fazem parte da gravação; e c) propriedades do som.

\section{a) Instrumentos que não fazem parte da gravação}

Considerando a comparação do antes e depois de cada criança, os resultados do teste não paramétrico para amostras pareadas de McNemar são apresentados na tabela abaixo:

Tabela 2: Resultado do teste não paramétrico para instrumentos que não fazem parte da gravação.

\begin{tabular}{cc}
\hline Categoria & p-valor \\
\hline Tambor & 0,0159 \\
\hline Piano & 0,0159 \\
\hline Sax & $>0,001$ \\
\hline Viola & $>0,001$ \\
\hline Bateria & $>0,001$ \\
\hline Violino & $>0,001$ \\
\hline Gaita & $>0,001$ \\
\hline Chocalho & $>0,001$ \\
\hline Violoncelo & $>0,001$ \\
\hline Baixo & $>0,001$ \\
\hline Sanfona & $>0,001$ \\
\hline Triângulo & $>0,001$ \\
\hline
\end{tabular}

Fonte: Oliveira Pinto (2020).

Como neste estudo foi considerado significante um $\alpha \leq 0,05$, então temos que todos os instrumentos que não fazem parte da formação da gravação apresentada às crianças tiveram uma resposta significativamente diferente entre a primeira e a segunda aplicação, diferenças essas tendendo para ser de redução das citações dos instrumentos após a intervenção (aulas).

\section{b) Instrumentos que fazem parte da gravação}

Os instrumentos presentes na gravação foram bandolim, cavaquinho, violão de sete cordas, pandeiro e flauta transversal; estes apareceram nessa ordem, um a um de forma acumulativa, na introdução da música. As proporções de citações dos instrumentos que fizeram parte da formação instrumental da gravação utilizada são apresentadas no gráfico a seguir: 


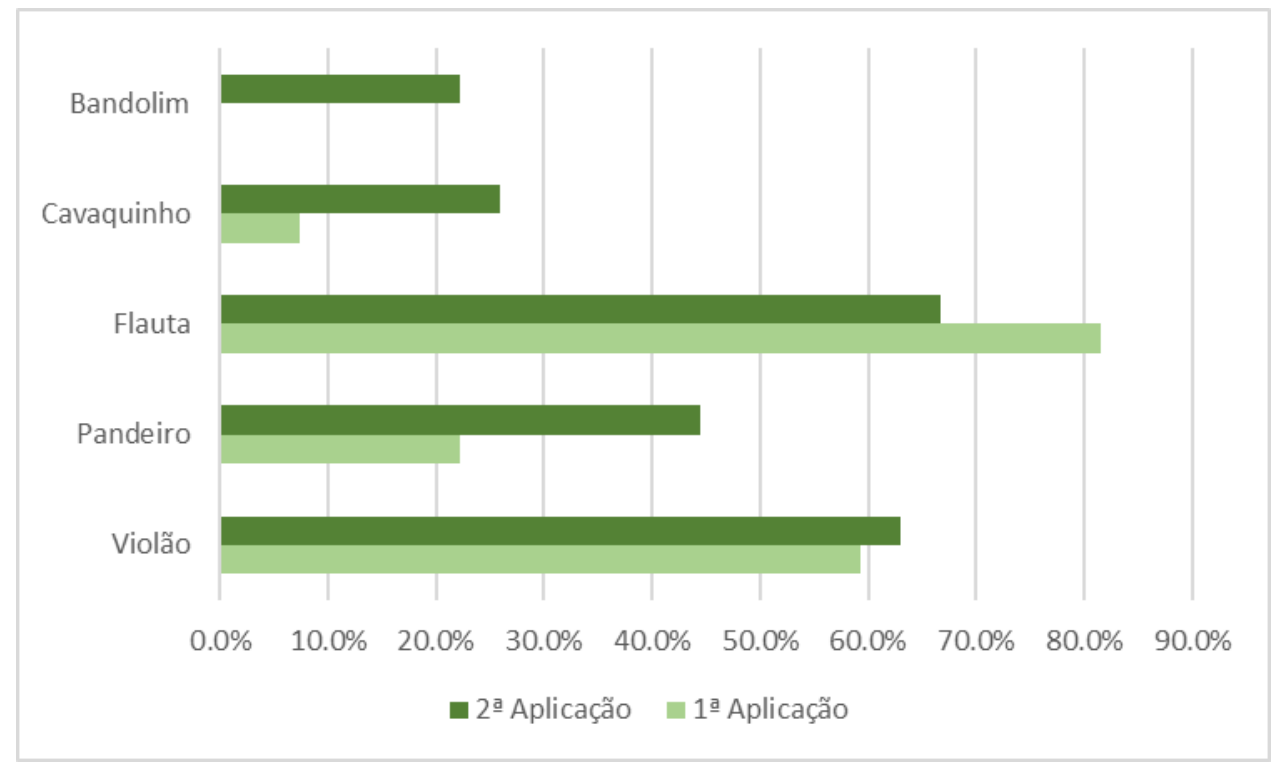

Figura 1: Materiais Sonoros - instrumentos que fazem parte da gravação. Fonte: Oliveira Pinto (2020).

Desses cinco instrumentos, apenas a flauta foi menos citada na segunda aplicação em relação à primeira. O bandolim não foi citado na primeira aplicação, mas após a intervenção um pouco mais de $20 \%$ das crianças o mencionaram. O gráfico acima mostra a frequência total das respostas, sem estar atrelada à evolução da criança entre os dois periodos.

Considerando a comparação do antes e depois de cada criança, os resultados do teste não paramétrico para amostras pareadas de McNemar são apresentados na tabela abaixo:

Tabela 3: Resultado do teste não paramétrico para instrumentos que fazem parte da gravação.

\begin{tabular}{cc}
\hline Categoria & p-valor \\
\hline Violão & 0,1814 \\
\hline Pandeiro & 0,0265 \\
\hline Flauta & $>0,001$ \\
\hline Cavaquinho & $>0,001$ \\
\hline Bandolim & $>0,001$ \\
\hline
\end{tabular}

Fonte: Oliveira Pinto (2020).

Neste estudo foi considerado significante um $\alpha \leq 0,05$, então temos que, entre os instrumentos que fizeram parte da formação instrumental da gravação, apenas o violão não apresentou mudanças significativas na distribuição de antes e depois da intervenção (aulas). Os demais instrumentos apresentaram evidências significativas de mudanças da distribuição após as aulas. 


\section{c) Propriedades do som}

Altura, intensidade e duração (caracterizada nas respostas pelo andamento e, portanto, esta categoria será assim nomeada) foram as propriedades que figuraram entre as respostas. Devido à forma que a resposta foi elaborada pelas crianças, poucas respostas foram obtidas para cada uma das propriedades, ou seja, foi considerado se a criança citou ou não alguma característica do som. Na figura abaixo temos a proporção de crianças que sinalizaram as categorias altura, intensidade e andamento na primeira e na segunda aplicação do questionário:

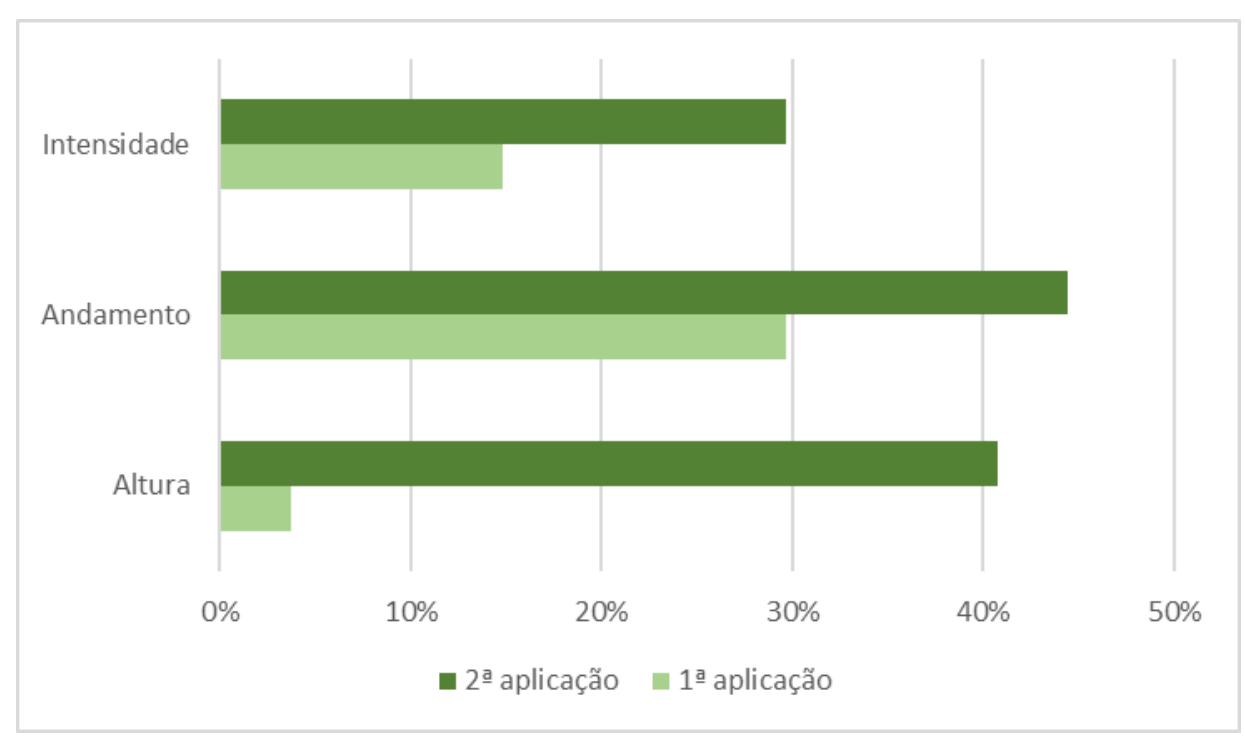

Figura 2: Materiais Sonoros - propriedades do som. Fonte: Oliveira Pinto (2020).

O gráfico acima mostra um aumento em relação à percepção das três categorias após a intervenção (aulas). Considerando a comparação do antes e depois de cada criança, os resultados do teste não paramétrico para amostras pareadas de McNemar são apresentados na tabela abaixo:

Tabela 4: Resultado do teste não paramétrico para as propriedades do som.

\begin{tabular}{cc}
\hline Categoria & p-valor \\
\hline Altura & $>0,001$ \\
\hline Intensidade & 0,001 \\
\hline Andamento & 0,121 \\
\hline
\end{tabular}

Fonte: Oliveira Pinto (2020).

Como nesse estudo foi considerado significante um $\alpha \leq 0,05$, então temos que a categoria andamento não apresentou uma diferença significativa entre 
as duas aplicações. Já as categorias altura e intensidade apresentam diferenças estatisticamente significantes entre as duas aplicações, indicando que as aulas podem ter influenciado a percepção dos alunos em relação a essas duas características do som.

\section{INSTÂNCIA FORMA}

Com relação à instância Forma, as respostas para a pergunta "Como são as partes da música?" puderam ser classificadas em quatro categorias: contraste entre partes da música; percepção de partes iguais e/ou repetições; percepção de partes diferentes; e nomenclatura. Cada categoria é exemplificada abaixo:

- Contraste entre as partes da música:

"é bem devagar e de repente acelerou e as partes não foram iguais"

- Partes iguais e/ou repetições:

"algumas partes da música são repetidas muitas vezes"

- Partes diferentes:

"ela não tem partes iguais"

- Nomenclatura:

"a letra A repete e a letra $B$ não e a $C$ também"

Na figura abaixo temos a proporção de crianças que sinalizaram as categorias contraste, partes iguais, partes diferentes e nomenclatura na primeira e na segunda aplicação do questionário:

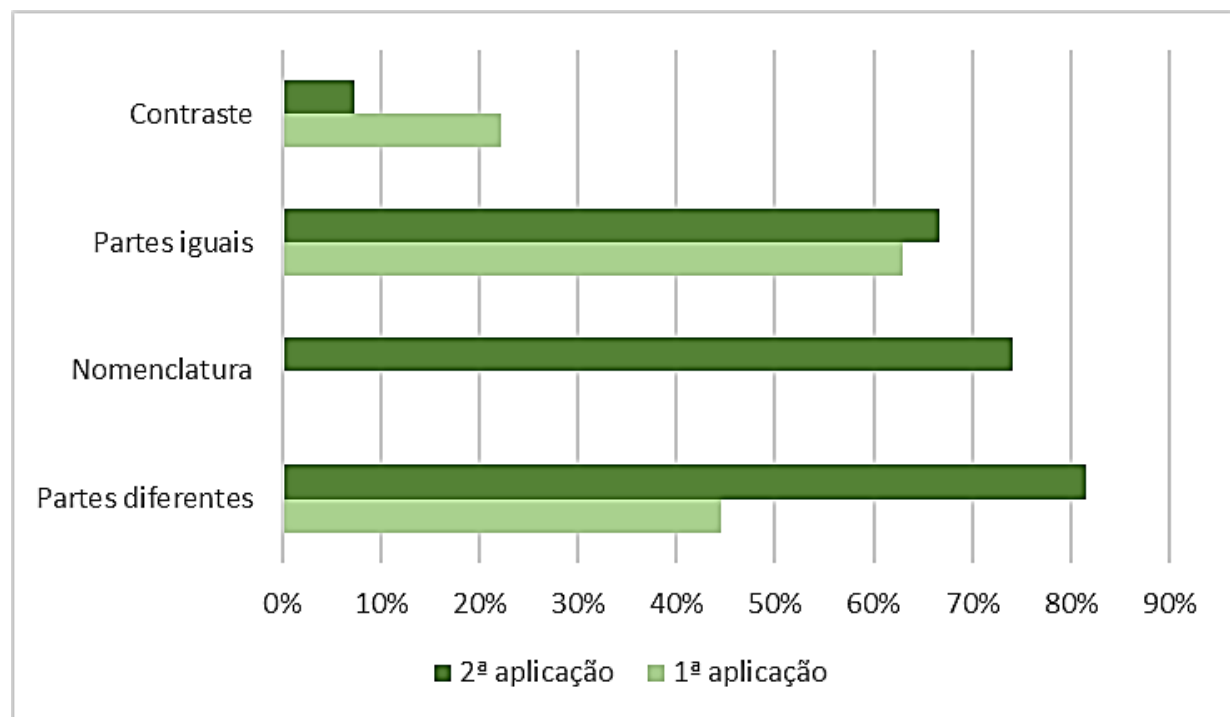

Figura 3: Forma. Fonte: Oliveira Pinto (2020).

O gráfico acima mostra que as menções em relação ao contraste das partes das músicas diminuíram na segunda coleta de dados. A categoria nomenclatura, antes não utilizada pelos alunos, passou de nenhuma citação na primeira aplicação para mais de $80 \%$ dos alunos se utilizando dela na 
segunda aplicação. As categorias partes iguais e partes diferentes apresentaram um aumento na frequência de resposta. Esse gráfico mostra a frequência total das respostas, sem estar atrelada à evolução da criança entre os dois periodos. Considerando a comparação do antes e depois de cada criança, os resultados do teste não paramétrico para amostras pareadas de McNemar são apresentados na tabela abaixo:

Tabela 5: Resultado do teste não paramétrico para a Forma.

\begin{tabular}{cc}
\hline Categoria & p-valor \\
\hline Partes diferentes & 0,0961 \\
\hline Partes iguais & 0,0801 \\
\hline Nomenclatura & 0,0233 \\
\hline Contraste & $>0,001$ \\
\hline
\end{tabular}

Fonte: Oliveira Pinto (2020).

Como neste estudo foi considerado significante um $\alpha \leq 0,05$, então temos que as categorias partes diferentes e partes iguais não apresentaram diferenças significativas na distribuição de antes da intervenção e depois da intervenção. A categoria nomenclatura apresentou uma diferença significativa entre as duas aplicações com o aumento das citações na segunda aplicação. Já para a categoria contraste existe uma evidência de diferença significativa entre a primeira e a segunda intervenção, porém essa diferença é a de que menos crianças citaram o contraste na segunda aplicação.

\section{INSTÂNCIA CARÁTER EXPRESSIVO}

"O que essa música fez você imaginar?" foi a pergunta colocada, e a diversidade das respostas dos alunos com relação ao caráter expressivo resultou em cinco categorias: imagem fixa; movimento; interação entre duas coisas; sentimentos animados; e músicos tocando. Cada categoria é exemplificada abaixo:

- Imagem fixa:

"uma foto do Cristo Redentor"

- Movimento:

"uma pessoa dançando e cozinhando"

- Interação entre duas coisas:

"um gato atrás de um rato"

- Sentimentos animados: "coisas legais e divertidas"

- Músicos tocando: "fez eu imaginar um baterista, pianista, flautista, saxofonista" 
Apesar de citadas, as baixas ocorrências sobre as categorias sentimentos animados e músicos tocando não possibilitaram a análise quantitativa das mesmas, portanto, nesta análise foram consideradas as categorias imagem fixa, movimento e interação entre duas coisas. Na figura abaixo temos a proporção de crianças que sinalizaram as categorias da instância Caráter Expressivo na primeira e na segunda aplicação do questionário.

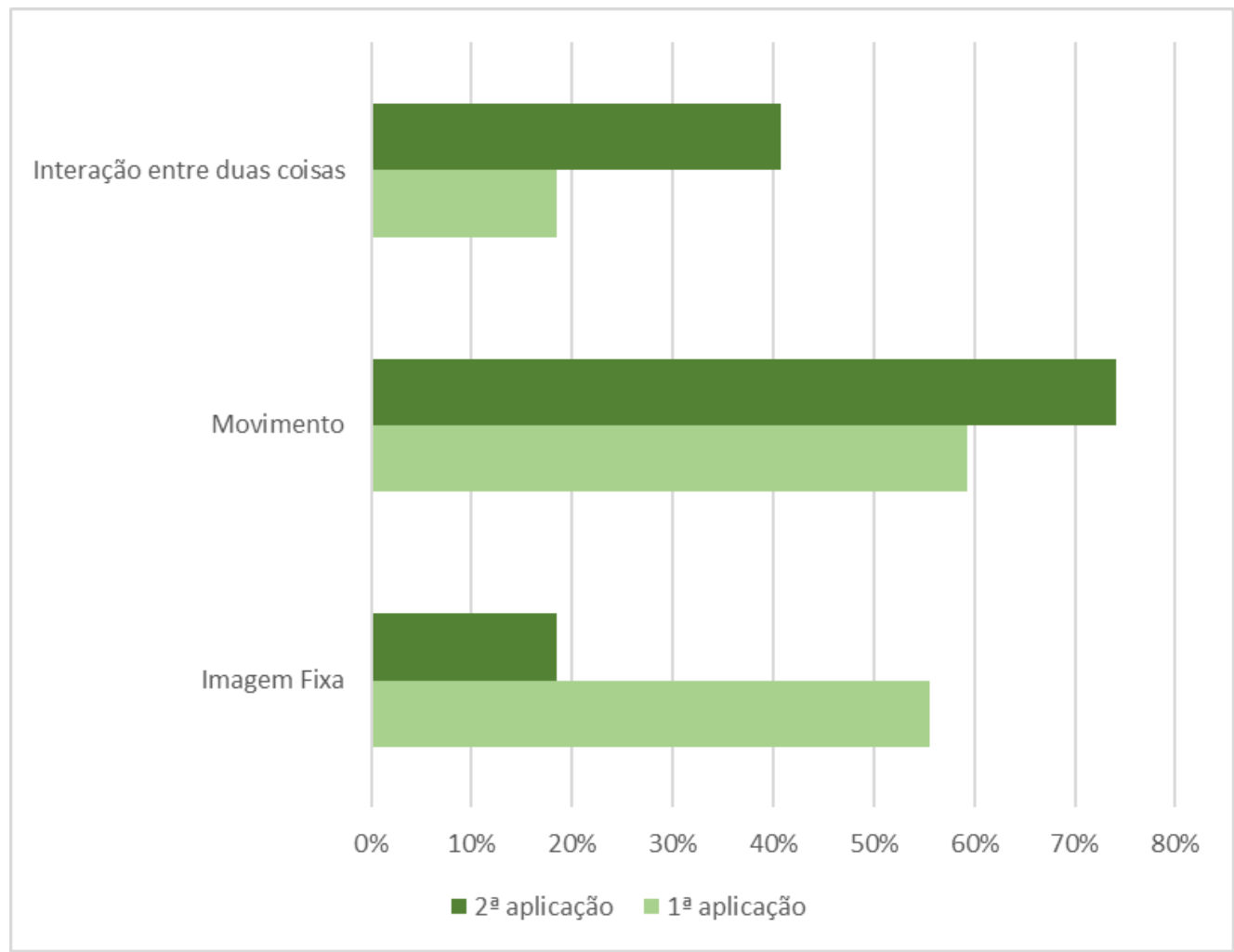

Figura 4: Caráter Expressivo. Fonte: Oliveira Pinto (2020).

A categoria imagem fixa foi a única que apresentou uma redução de respostas na comparação entre as duas aplicações, enquanto as categorias movimento e interação entre duas coisas apresentaram um aumento de respostas na segunda aplicação. O gráfico mostra a frequência total das respostas, sem estar atrelado à evolução da criança entre os dois períodos. Considerando a comparação do antes e depois de cada criança, os resultados do teste não paramétrico para amostras pareadas de McNemar são apresentados na tabela abaixo:

Tabela 6: Resultado do teste não paramétrico para o Caráter Expressivo.

\begin{tabular}{cc}
\hline Categoria & p-valor \\
\hline Imagem fixa & 0,1213 \\
\hline Movimento & 0,0389 \\
\hline Interação entre duas coisas & 0,0218 \\
\hline
\end{tabular}

Fonte: Oliveira Pinto (2020). 
Como neste estudo foi considerado significante um $\alpha \leq 0,05$, então temos que a categoria imagem fixa não apresentou diferença significativa na distribuição de antes da intervenção e depois da intervenção. Para as demais categorias existe uma evidência de diferença significativa entre o periodo antes e o período depois da intervenção.

Tabela 7: Imagem fixa.

\begin{tabular}{cccc}
\hline \multirow{2}{*}{ Segunda aplicação } & \multicolumn{3}{c}{ Primeira aplicação } \\
\cline { 2 - 4 } & $0-$ não citou & $1-$ citou & Total \\
\hline 0 - não citou & 11 & 11 & 22 \\
\hline 1 - citou & 1 & 4 & 5 \\
\hline Total & 12 & 15 & 27 \\
\hline qui-quadrado: & & & \\
\hline p-valor: & 2.4000 & \\
\hline
\end{tabular}

Fonte: Oliveira Pinto (2020).

Tabela 8: Movimento.

\begin{tabular}{cccc}
\hline \multirow{2}{*}{ Segunda aplicação } & \multicolumn{3}{c}{ Primeira aplicação } \\
\cline { 2 - 4 } & $0-$ não citou & 1 - citou & Total \\
\hline 0 - não citou & 3 & 4 & 7 \\
\hline 1 - citou & 8 & 12 & 20 \\
\hline Total & 11 & 16 & 27 \\
\hline qui-quadrado: & 4.2667 & \\
\hline p-valor: & 0.0389 & \\
\hline
\end{tabular}

Fonte: Oliveira Pinto (2020).

Tabela 9: Interação entre duas coisas.

\begin{tabular}{cccc}
\hline \multirow{2}{*}{ Segunda aplicação } & \multicolumn{3}{c}{ Primeira aplicação } \\
\cline { 2 - 4 } & $0-$ não citou & $1-$ citou & Total \\
\hline 0 - não citou & 15 & 1 & 16 \\
\hline 1 - citou & 7 & 4 & 11 \\
\hline Total & 22 & 5 & 27 \\
\hline \multicolumn{4}{c}{} \\
\hline qui-quadrado: & 5.2632 & \\
\hline p-valor: & 0.0218 & \\
\hline
\end{tabular}

Fonte: Oliveira Pinto (2020). 
A intervenção (aulas de música ministradas) não apresentou resultados estatisticamente diferentes na percepção na categoria imagem fixa. Nas categorias movimento e interação entre duas coisas houve uma diferença estatística significativa, apontando para um aumento na percepção desses atributos na música após as aulas ministradas.

A música utilizada para a aplicação do questionário foi o já citado choro “1 x 0" de Pixinguinha, que tem como característica o caráter virtuoso dado pelo andamento rápido, pelos saltos melódicos e pela predominância da região aguda (Bessa, 2005). Foi composto em 1919, inspirado por uma partida de futebol, onde o Brasil venceu o Uruguai pelo placar que dá nome ao choro. Diferentes versões relacionam Pixinguinha com esse jogo; se ele estaria no estádio ou então em casa, ouvindo a transmissão pelo rádio. Um possível consenso é a origem onomatopaica desse choro, cujo motivo rítmico melódico presente na parte A faz referência a uma gaitinha, uma espécie de flauta de Pã que Ary Barroso utilizava para sinalizar o gol do Brasil (Bessa, 2005; Carrilho, 2007 apud Amado, 2016). A partir desse motivo, o compositor articulou um discurso musical, apoiando-se em um descritivismo sonoro, aludindo ao jogo, aos dribles e ao momento do gol (Bessa, 2005).

Swanwick (1994, p. 134, tradução nossa) relaciona o movimento estimulado pela música com o caráter expressivo da seguinte forma:

\footnotetext{
Mover-se com a música parece ser uma atividade fortemente análoga, uma forma de análise que fica próxima às propriedades expressivas e estruturais móveis da música: tempo, ritmo, peso e fluxo são realidades psicológicas em ambos, movimento e música. O movimento parece promover o conhecimento musical $[\ldots]$.
}

A análise das respostas mostrou que, por meio da apreciação musical ativa, foi possivel contribuir para a percepção do caráter expressivo desse choro. As atividades desenvolvidas consideraram o aspecto ora discursivo, ora descritivo, ora brincalhão do gênero (Camargo, 2004; Lopes, 2019; Piedade, 2011), e também o aprendizado pela prática e a improvisação.

\section{CONSIDERAÇÕES}

Ampliar o repertório, a escuta, a compreensão e o fazer musical coletivo foram objetivos buscados pela pesquisa, que evidenciou as oportunidades que o repertório instrumental do choro oferece no contexto do ensino básico, em especial nos anos iniciais. É essencial, nessa etapa do ensino, que as experiências, repertórios e fazeres sejam diversificados, significativos e que oportunizem a expressividade individual e coletiva dos alunos. Sobre o ensino de Arte, a BNCC apresenta:

Ao longo do Ensino Fundamental, os alunos devem expandir seu repertório e ampliar sua autonomia nas práticas artísticas, por meio da reflexão sensivel, imaginativa e crítica sobre os 
conteúdos artísticos e seus elementos constitutivos e também sobre as experiências de pesquisa, invenção e criação (Brasil, 2017, p. 197).

A expansão do repertório pode iniciar com um gênero, que servirá de ponto de partida para outras músicas e sonoridades. A partir da temática música instrumental podem derivar propostas sobre grupos instrumentais locais, trilhas sonoras de desenhos, filmes, jogos, música eletrônica, entre outras. O envolvimento ativo do aluno nesse processo é pertinente, e o seu espaço de expressão e autonomia pode ser garantido por meio das oportunidades de criação.

Os meios da ativação da escuta - o uso do corpo, da voz, do movimento, de instrumentos, propostos por Wuytack e Palheiros (1995) - foram os expedientes pelos quais se buscou garantir a natureza experiencial do choro e, também, a ludicidade e o prazer do fazer musical. Ao valorizar o conteúdo sonoro e expressivo da música instrumental brasileira, a apreciação musical ativa do choro nas aulas de música possibilitou uma ampliação do referencial musical das crianças, e estimulou o desenvolvimento de uma compreensão e apropriação simbólica da música.

\section{REFERENCIAS}

ALMEIDA, Berenice; LEVY, Gabriel. Livro de brincadeiras musicais da Palavra Cantada: livro do professor. São Paulo: Melhoramentos, 2010.

ALVES DA SILVA, Lélio Eduardo. Musicalização através da banda de música escolar. uma proposta de metodologia de ensaio fundamentada na análise do desenvolvimento musical dos seus integrantes e na observação da atuação dos "Mestres da banda". 2010. Tese (Doutorado em Música) Centro de Letras e Artes, Universidade Federal do Estado do Rio de Janeiro, Rio de Janeiro, 2010.

AMADO, Paulo Vinícius. Um a Zero de Pixinguinha: uma compreensão e interpretação a partir da ideia de um choro programático. In: CONGRESSO DA ASSOCIAÇÃO BRASILEIRA DE PERFORMANCE MUSICAL (ABRAPEM), 4., 2016, Campinas. Anais [...]. Campinas: Unicamp, 2016. p. 224-231.

AMARAL, Maria Luiza Ferreira; CORDEIRO, Djalma; GOULART, Gustavo Pires. A prática musical dos gêneros brasileiros choro, samba e baião inseridos na educação básica frente à influência da mídia. In: CONGRESSO NACIONAL DA ASSOCIAÇÃO BRASILEIRA DE EDUCAÇÃO MUSICAL, 19., 2010, Goiânia. Anais [...]. Goiânia: Abem, 2010. p. 335-342.

ASSIS, Ana Cláudia de; BARBEITAS, Flávio; LANA, Joana; CARDOSO FILHO, Marcos Edson. Música e História: desafios da prática interdisciplinar. In: BUDASZ, Rogério (org.). Pesquisa em música no Brasil: métodos, domínios, perspectivas. Goiânia: Anppom, 2009. p. 5-39. 
BERTHO, Renan Moreti; JOLY, Ilza Zenker Leme. Chorando com a flauta doce. In: CONGRESSO NACIONAL DA ASSOCIAÇÃO BRASILEIRA DE EDUCAÇÃO MUSICAL, 19., 2010, Goiânia. Anais [...]. Goiânia: Abem, 2010. p. 581-588.

BESSA, Virginia de Almeida. Um bocadinho de cada coisa: trajetória e obra de Pixinguinha. História e música popular no Brasil dos anos 20 e 30. 2005. Dissertação (Mestrado em História Social) - Faculdade de Filosofia, Letras e Ciências Humanas, Universidade de São Paulo, São Paulo, 2005. DOI: 10.11606/D.8.2006.tde-21032007-151952.

BRASIL, Ministério da Educação. Base nacional comum curricular. Brasília, DF: MEC, 2017.

CAMARGO, Luis Francisco Espindola. Choro: enunciado e ajunstamento. Revista de Estudos Poético-Musicais, Florianópolis, n. 1, maio 2004. Disponivel em: https:/ / www.repom.ufsc.br/REPOM1/chico.htm. Acesso em: 27 ago. 2020.

CAREGNATO, Caroline. Relações entre a teoria espiral do desenvolvimento musical e a epistemologia genética. Schème: Revista Eletrônica de Psicologia e Epistemologia Genéticas, Marília, v. 5, n. 1, p. 128-146, jan./jul. 2013.

CURITIBA. Secretaria Municipal da Educação. Plano curricular Arte $-1^{\circ}$ ao $5^{\circ}$ ano. Curitiba: SME, 2016.

CURY, Carlos Roberto Jamil. A educação básica como direito. Cadernos de Pesquisa, São Paulo, v. 38, n. 134, p. 293-303, ago. 2008. Disponivel em: http:/ / www.scielo.br/scielo.php?script=sci_arttext\&pid=S010015742008000200002\&lng=en\&nrm=iso. Acesso em: 27 ago. 2020.

DINIZ, André. Almanaque do choro: a história do chorinho, o que ouvir, o que ler, onde curtir. 3. ed. Rio de Janeiro: Jorge Zahar, 2003.

FUCCI-AMATO, Rita. Escola e educação musical: (des)caminhos históricos e horizontes. Campinas: Papirus Editora, 2012.

GREEN, Lucy. Music, informal learning and the school: a new classroom pedagogy. London: Ashgate, 2008.

. Ensino da música popular em si, para si mesma e para "outra" música: uma pesquisa atual em sala de aula. Revista da Abem, Londrina, v. 20, n. 28, 2012.

ILARI, Beatriz. Música na infância e na adolescência: um livro para pais, professores e aficionados. Curitiba: Ibpex, 2009.

LOPES, Mário Sève Wanderley. A retórica musical e o choro. Música Popular em Revista, Campinas, ano 6, v. 1, p. 56-91, jan./jul. 2019. 
MAFFIOLETTI, Leda de Albuquerque. Diferenciações e integrações: o conhecimento novo na composição musical infantil. 2005. Tese (Doutorado em Educação) - Faculdade de Educação, Universidade Federal do Rio Grande do Sul, Porto Alegre, 2005.

MÁXIMO-ESTEVES, Lidia. Visão panorâmica da investigação-acção. Porto: Porto Editora, 2008.

OLIVEIRA PINTO, Camile Tatiane de. O choro na educação básica: a construção do conhecimento musical por meio da apreciação do repertório do choro. Dissertação (Mestrado em Música) - Setor de Artes, Comunicação e Design, Universidade Federal do Paraná, Curitiba, 2020.

PENNA, Maura. A função dos métodos e o papel do professor: em questão, "como" ensinar música. In: MATEIRO, Teresa; ILARI, Beatriz (org.). Pedagogias em educação musical. Curitiba: Ibpex, 2013.

PETERS, Ana Paula. Nas trilhas do choro. Curitiba: Máquina de Escrever, 2016.

PIEDADE, Acácio. Perseguindo fios da meada: pensamentos sobre hibridismo, musicalidade e tópicas. Per Musi, Belo Horizonte, n. 23, p. 103$112,2011$.

QUEIROZ, Luis Ricardo Silva. Traços de colonialidade na educação superior em música do Brasil: análises a partir de uma trajetória de epistemicídios musicais e exclusões. Revista da Abem, Londrina, v. 25, n. 39, p. 132-159, 2017.

ROMANELLI, Guilherme Gabriel Ballande. A música que soa na escola: estudo etnográfico nas séries iniciais do ensino fundamental. 2009. Tese (Doutorado em Educação) - Setor de Educação, Universidade Federal do Paraná, Curitiba, 2009.

SANDRONI, Carlos. Uma roda de choro concentrada: reflexões sobre o ensino de músicas populares nas escolas. In: ENCONTRO ANUAL DA ABEM, 9., 2000, Belém. Anais [...]. Belém: Abem, 2000. p. 19-26.

SIEGEL, Sidney. Estatistica não-paramétrica para as ciências do comportamento. São Paulo: McGrawHill, 1956.

SLOBODA, John. A mente musical: a psicologia definitiva da música. Tradução de Beatriz Ilari e Rodolfo Ilari. Londrina: Eduel, 2008.

SOUZA, Grazielle Mariana Louzada de. "De nova cara o velho choro": choro na contemporaneidade: perspectivas artísticas, sociais e educacionais. 2012. Dissertação (Mestrado em Estudos de Cultura Contemporânea) - Instituto de Linguagens, Universidade Federal de Mato Grosso, Cuiabá, 2012. 
SWANWICK, Keith. Musical knowledge: intuition, analysis and music education. London: Routledge, 1994.

Ensinando música musicalmente. Trad. Alda Oliveira e Cristina Tourinho. São Paulo: Moderna, 2003.

SWANWICK, Keith; TILLMAN, June. The sequence of musical development: a study of children's composition. British Journal of Music Education, Cambridge, v. 3, n. 3, p. 305-339, 1986.

WUYTACK, Jos; PALHEIROS, Graça Boal. Audição musical activa: livro do professor e livro do aluno. Porto: Associação Wuytack de Pedagogia Musical, 1995.

YAUNNER, Beatriz Stutz. O ensino do choro na educação básica: uma possibilidade. 2013. Dissertação (Mestrado em Música) - Escola de Música, Universidade Federal do Rio de Janeiro, Rio de Janeiro, 2013. 
Camile Tatiane de Oliveira Pinto é doutoranda e mestre em Música pela Universidade Federal do Paraná (UFPR) na linha de Cognição e Educação Musical. Possui graduação em Licenciatura e especialização em Educação Musical pela Universidade Estadual do Paraná (Unespar/ EMBAP). Professora de música, atua no curso de Licenciatura em Música, no ensino básico (educação infantil e ensino fundamental) e na iniciação instrumental de violino e flauta doce. Seus interesses de pesquisa são a música na educação básica, a avaliação em música e o ensino coletivo e a iniciação instrumental. https://orcid.org/0000-0001-8321-7181

Ana Paula Peters é professora da Universidade Estadual do Paraná (Unespar - campus Curitiba I - EMBAP), onde atua nos cursos de graduação em Licenciatura em Música e no Programa de Pós-Graduação em Música da Universidade Estadual do Paraná (Unespar), na linha de pesquisa Música, Cultura e Sociedade e no Programa de Pós-Graduação em Música da Universidade Federal do Paraná (UFPR), na linha de pesquisa Educação Musical/Cognição. Seus interesses de pesquisa incluem a música popular brasileira, os arquivos sonoros, a indústria fonográfica, a prática musical e as possibilidades de ensino do choro em sala de aula. É autora do livro Nas trilhas do choro (2016), publicado pelo Programa de Apoio e Incentivo à Cultura da Fundação Cultural de Curitiba e da Prefeitura de Curitiba, e da coleção de livros "Além das notas: música" que, em 2013, ficou entre as obras finalistas do Prêmio Jabuti, na categoria livros didáticos e paradidáticos. https://orcid.org/0000-0002-4530-3000 